\title{
Entrustable Professional Activities: An Analysis of Faculty Time, Trainee Perspectives, and Actionability
}

Victoria David, MD, MSc ${ }^{1}$, Michael Walsh, MD $^{2}$, Jocelyn Lockyer, PhD $^{3}$, Marcy Mintz, MD, MHPE, FRCPC ${ }^{2}$

\author{
${ }^{1}$ Division of Hematology and Thromboembolism, McMaster University, Hamilton, ON, Canada \\ ${ }^{2}$ Division of General Internal Medicine, University of Calgary, Calgary, AB, Canada \\ ${ }^{3}$ Department of Community Health Sciences, University of Calgary, Calgary, AB, Canada \\ Author for correspondence: Victoria David: vdavid@ucalgary.ca \\ Received: 3 January 2020; Accepted after revision: 6 April 2020; Published: 26 March 2021. \\ DOI: https://dx.doi.org/10.22374/cjgim.v16i1.415
}

\begin{abstract}
The Royal College of Physicians and Surgeons of Canada introduced Competence by Design (CBD) as an educational model along with Entrustable Professional Activities (EPAs) as markers of achievement that could be directly observed on a frequent basis. In 2017, the University of Calgary Internal Medicine (IM) program piloted CBD. The purpose of this study was to (1) assess whether written feedback from EPAs were actionable, valuable, and disruptive to workflow and (2) assess the time required to complete an EPA.
\end{abstract}

\section{Methods}

Seven Foundations of Discipline EPAs were used with 31 PGY-1 Calgary IM residents. The study used quantitative and qualitative data. Following a discussion on an EPA and completion of both the quantitative and written feedback, residents were asked to comment on the value of the encounter and the degree of disruption to workflow. Assessors provided time to complete an EPA. Data were anonymized. Trainee comments were coded for value and disruption, and assessor's written feedback was coded for actionability.

\section{Results}

One hundred and five EPA encounters were submitted. The majority of the comments provided to trainees were not actionable $(94.3 \%, \mathrm{n}=99 / 105)$. While most residents did not comment on value $(73.3 \%, \mathrm{n}=77 / 105)$ or disruption $(44.8 \%, \mathrm{n}=47 / 105)$ of the encounter, those that did generally found the encounters valuable $(25.7 \%, \mathrm{n}=27 / 105)$ and nondisruptive $(35.2 \%, \mathrm{n}=$ $37 / 105)$. A minority found the process nonvaluable $(1 \%, \mathrm{n}=1 / 105)$ and disruptive $(20 \%, \mathrm{n}=$ 21/105). The mean time to complete an EPA form and provide feedback was $8.6 \mathrm{~min}$.

\section{Conclusion}

Most written feedback was not actionable, suggesting a potential role for faculty development to guide assessors and help them coach trainees on EPAs. 


\section{RÉSUMÉ}

Le Collège royal des médecins et chirurgiens du Canada a introduit la compétence par conception (CPC) comme modèle d’enseignement, ainsi que les activités professionnelles confiables (APC) comme marqueurs de réussite qui pourraient être observés directement et souvent. En 2017, le programme de médecine interne (MI) de l'Université de Calgary a testé la CPC. L'objectif de cette étude était : 1) d'évaluer si la rétroaction écrite des APC était exploitable, utile et perturbatrice pour le déroulement du travail; 2) d'évaluer le temps nécessaire pour mener à bien une APC.

\section{Méthodes}

Sept APC d'acquisition des fondements de la discipline ont été utilisées chez 31 résidents de première année en MI de l'Université de Calgary. Létude a utilisé des données quantitatives et qualitatives. Après avoir discuté d'une APC et terminé la rétroaction quantitative et écrite, les résidents ont été invités à faire des commentaires sur l'utilité de la rencontre et le degré de perturbation du déroulement du travail. Les évaluateurs ont accordé du temps pour compléter une APC. Les données ont été anonymisées. Les commentaires des stagiaires ont été codés en fonction de l'utilité et du degré de perturbation, et la rétroaction écrite des évaluateurs a été codée en fonction de l’exploitabilité.

\section{Résultats}

Au total, 105 rencontres d'APC ont été soumises. La majorité des commentaires fournis aux stagiaires nétaient pas exploitables $(94,3 \%, \mathrm{n}=99 / 105)$. Bien que la plupart des résidents n’aient pas fait de commentaires sur l'utilité $(73,3 \%, \mathrm{n}=77 / 105)$ ou la perturbation $(44,8 \%, \mathrm{n}=47 / 105)$ de la rencontre, ceux qui l'ont fait ont généralement trouvé les rencontres très utiles $(25,7 \%, \mathrm{n}=$ $27 / 105)$ et non perturbatrices $(35,2 \%, \mathrm{n}=37 / 105)$. Une minorité a trouvé le processus inutile ( 1 $\%, \mathrm{n}=1 / 105)$ et perturbateur $(20 \%, \mathrm{n}=21 / 105)$. Le temps moyen pour remplir un formulaire d'APC et fournir une rétroaction était de 8,6 minutes.

\section{Conclusion}

La plupart des rétroactions écrites nétaient pas exploitables, ce qui suggère un rôle que pourrait jouer le perfectionnement du corps professoral afin de guider les évaluateurs et de les aider à encadrer les stagiaires qui effectuent les APC.

\section{Introduction}

Residency education in Canada and internationally has evolved with the advent of competency-based medical education (CBME), which calls for medical education to be based on the health needs of the populations served, a focus on learner outcomes, and seamless formation of the physician across the continuum of education, training, and practice. ${ }^{1}$ Inherent in the change to CBME is the need for new and different systems of assessment and training of assessors to ensure that residents progress efficaciously from first year through to independent practice. ${ }^{2,3}$

In Canada, the Royal College of Physicians and Surgeons of Canada (RC) developed Competence by Design (CBD), a Canadian version of CBME, which requires that trainees "show how" and demonstrate the ability to "do" independently. This requires that frontline clinical teachers observe and document authentic observations in the workplace on a regular basis. Results of individual and aggregated data are shared to guide learning improvement and give programs a clearer picture about resident's performance and progress through the four stages of Transition to Discipline, Foundations of Discipline, Core of Discipline, and Transition to Practice., ${ }^{4,5}$

With CBD, residency training is broken into stages, and each stage is composed of multiple Entrustable Professional Activities (EPAs) and milestones. An EPA is a task of a discipline. It can be delegated to a resident or allied health care professional). And observed by an assessor (faculty or senior resident). Each EPA integrates several milestones as physicians use multiple abilities simultaneously when performing professional activities. ${ }^{4,5}$ EPAs 
utilize qualitative feedback and the CanMEDS framework to assess whether a resident has achieved specific core competencies and whether they are entrusted to perform this task independently.

The use of EPAs for feedback and training is relatively new and there is evolving information available to guide the use of EPA assessment in clinical practice.In disciplines such as Internal Medicine (IM) and General IM, which have only recently transitioned to $\mathrm{CBD}$, there is a need to conduct research that will inform and enable adjustments throughout implementation. Concern has been expressed about the increased daily workload for residents and assessors with a disrupted workflow as well as learner receptivity of feedback. ${ }^{6-10}$ From an assessor perspective, little is known about the time required to complete an encounter or the characteristics of the narrative comments provided. From a resident perspective, it is unclear whether feedback improves future performance. Feedback can be compromised by perceptions that it lacks utility, detail, clarity, individualization, and can't be implemented or recalled. ${ }^{1,11,12}$ This highlights the importance of feedback actionability, or the extent to which recipients can use their feedback to identify what they can do to direct future behavior. ${ }^{1,11,12}$

The primary purposes of this study were to characterize EPA encounters in terms of the feedback received. Specifically, our research questions were:

1. Is the written feedback provided in EPAs actionable?

2. Do residents find the process of EPAs valuable?

3. Do residents find the process of EPAs disruptive?

4. How long does it take to complete an EPA encounter?

\section{Methods}

The study used both quantitative and qualitative data.

The Internal Medicine Residency Program (IMRP) at the University of Calgary prepared for the transition to CBD by initiating mandatory directly observed EPA encounters ahead of the formal transition to CBD. This was initiated with the postgraduate year one (PGY-1) cohort focusing on the Foundations of Discipline EPAs. The Foundations of Discipline phase has multiple EPAs that assess resident performance in specific aspects of their specialty.

Between April and June 2017, seven Foundations to Discipline EPAs were introduced to 31 PGY-1 residents at the University of Calgary (Table 1). During a discussion between the resident and the assessor, an EPA form was completed providing the resident with both quantitative and written feedback. The time to complete an EPA was self-reported by the assessor for each EPA submitted.

The EPA forms were built in Office 365 software and were available online to all residents and assessors. An example of the EPA 1: "Assessing, diagnosing, and providing initial management for patients in acute care" is provided in Table 2. Data entered via these forms were compiled using Excel software. The following questions were added at the bottom of the EPA forms for the resident to complete: Was this a valuable educational encounter? Did this process disrupt workflow? In addition to filling out the assessment, assessors would answer: How long did the process take?

Table 1. Internal medicine foundations of discipline entrustable professional activities and the number of EPAs submitted for each type of EPA.

\begin{tabular}{|l|l|c|}
\hline Entrustable professional activities & Number completed \\
\hline EPA 1 & $\begin{array}{l}\text { Assessing, diagnosing, and providing initial management for } \\
\text { patients with common acute medical presentations in acute care } \\
\text { settings. }\end{array}$ & $27.6 \%(29 / 105)$ \\
\hline EPA 2 & $\begin{array}{l}\text { Managing patients admitted to acute care settings with common } \\
\text { medical problems and advancing their care plans. }\end{array}$ & $23.8 \%(25 / 105)$ \\
\hline EPA 3 & $\begin{array}{l}\text { Consulting specialists and other health professionals, synthesizing } \\
\text { recommendations, and integrating these into the care plan. }\end{array}$ & $1.6 \%(8 / 105)$ \\
\hline EPA 4 & $\begin{array}{l}\text { Formulating, communicating, and implementing discharge plans for } \\
\text { patients with common medical conditions in acute care settings. }\end{array}$ & $9.5 \%(10 / 105)$ \\
\hline EPA 5 & $\begin{array}{l}\text { Assessing unstable patients, providing targeted treatment and } \\
\text { consulting as needed. }\end{array}$ & $6.7 \%(7 / 105)$ \\
\hline EPA 6 & Discussing and establishing patients' goals of care. & $11.4 \%(12 / 105)$ \\
\hline EPA 7 & $\begin{array}{l}\text { Identifying personal learning needs while caring for patients and } \\
\text { addressing those needs. }\end{array}$ & \\
\hline
\end{tabular}


Table 2. An example of entrustable professional activity 1: assessing, diagnosing, and providing initial management for patients with common acute medical presentations in acute care settings.

1. Name of RESIDENT being assessed

2. Date of assessment

3. Training level of evaluator (i.e., PGY2, 3, 4, 5, or Faculty) AND name of evaluator

4. Location and type of patient (inpatient/outpatient; new or follow-up patient)

5. Patient diagnosis

6. The observation was either DIRECT or INDIRECT

7. Assessment of the trainee's performance in their ability to complete a patient's admission (Options: Achieved, In Progress, or Not Observed)

Comments:

8. Assessment of the trainee's performance in their ability to generate a differential diagnosis along with appropriate diagnostic strategies (Options: Achieved, In Progress, or Not Observed) Comments:

9. Assessment of the trainee's performance in their ability to implement initial management plans (Options: Achieved, In Progress, or Not Observed)

Comments:

10. Entrustment (Options: I had to talk the trainee through the encounter, I needed to prompt, I needed to be there just in case, I didn't need to be present)

11. Time required to provide feedback and to complete the form (minutes)

12. General feedback by the TRAINEE being evaluated, that is, Was it difficult to find time to be evaluated? Was this helpful? Did it disrupt your workflow? (free text)

Submitted data were anonymized and entered into a spreadsheet. Two researchers received the anonymized dataset, which included the EPA, the EPA quantitative data, and free-text comments and answers on the value, length, and disruption of the process. They then coded the assessor's free text for actionability using a score of 0 for nonactionable, 1 for partly actionable, and 2 for actionable. Trainee comments were coded for value and disruption using the coding of 0 for nonvaluable or disruptive, 1 for indeterminate, and 2 for valuable or nondisruptive. The researchers worked independently by coding the data. Differences in coding for value, disruption, and actionability were identified and discussed, and resolved through discussion.

The coded data were used for analysis to answer the study questions. For the primary research questions on actionability, value, and disruption of EPA evaluations, a descriptive analysis of the data was conducted to determine the number of EPA encounters that contained actionable feedback, were valuable, and were not disruptive.

This study was submitted to the University of Calgary Conjoint Health Research Ethics Board who waived ethics approval by classifying the project as one concerning Quality Assurance.

\section{Results}

In total, 28 out of 31 residents (90.3\%) in the PGY-1 cohort submitted a total of 105 EPAs. Table 1 lists the number of EPAs submitted for each type of EPA. Residents were entrusted in the majority of EPA encounters $(91.4 \%, 96 / 105)$. Table 3 provides a further breakdown on the level of entrustment for the EPA encounters. Residents submitted a mean of 3.4 EPAs (s.d. = 1.9) with a median of 3 EPAs. The mean time to complete an EPA form and provide feedback as reported by assessors was $8.6 \mathrm{~min}$ (s.d. = $10.1 \mathrm{~min}$ ). The median time to complete an EPA form and provide feedback was $5 \mathrm{~min}$, with a range between $1 \mathrm{~min}$ and $75 \mathrm{~min}$. The majority of the comments provided in an encounter were not actionable $(94.3 \%, \mathrm{n}=99 / 105)$. EPA 4 had the most

Table 3. Entrustment level by EPA encounter.

\begin{tabular}{|l|l|}
\hline Level of entrustment & \\
\hline Entrusted as "I didn't need to be there" & $73.3 \%(77 / 105)$ \\
\hline Entrusted as "I needed to be there in case" & $18.1 \%(19 / 105)$ \\
\hline Not entrusted & $8.6 \%(9 / 105)$ \\
\hline
\end{tabular}


actionable feedback $(21.4 \%, \mathrm{n}=3 / 14)$. Examples of actionable and nonactionable written feedback are provided in Table 4. Of the EPA encounters where residents were not entrusted, $22.2 \%$ (2/9) had actionable written feedback.

The majority of the encounters when assessed for value were coded as indeterminate as no data were provided by the residents $(73.3 \%, \mathrm{n}=77 / 105)$. When residents provided input on value, $25.7 \%$ of encounters were coded as valuable $(n=27 / 105)$, and $1 \%$ was coded as nonvaluable $(\mathrm{n}=1 / 105)$. The majority of encounters were coded as indeterminate for disruption as no data were provided by the resident $(44.8 \%, \mathrm{n}=47 / 105)$. When residents provided input on disruption, $35.2 \%$ of encounters were coded as nondisruptive $(\mathrm{n}=37 / 105)$ and $20 \%$ were coded as disruptive $(\mathrm{n}=21 / 105)$.

\section{Discussion}

This study aimed to better characterize CBD implementation within the core IMRP at the University of Calgary. This study is unique in that it captures insight into the transition to CBD from a resident perspective. It highlights the value which Calgary internal medicine trainees place on EPA evaluations and provides insight on written EPA feedback from a PGY-1 cohort. It also identifies the lack of actionable written feedback, regardless of whether the resident was entrusted or not. Calgary trainees who provided input did not find that EPAs disrupted workflow and found the process to be valuable. Time to complete an EPA was widely variable.

The majority of written feedback was not actionable, which is aligned with findings from a study conducted at another Canadian IM residency program, which found that the quality of EPA feedback was lacking. ${ }^{11}$ It is difficult to know why there was a lack of actionability in the written feedback. It is possible that assessors are providing actionable feedback verbally but not documenting it. Residents do prefer verbal feedback over written feedback, but providing both is important. ${ }^{13}$ Others have noted that feedback can be compromised by perceptions that it lacks utility, details, clarity, individualization, and can't be implemented or recalled. ${ }^{14,15}$ Faculty may also be uncertain on how to individualize and provide feedback as high-performing residents may need to enhance skills while those who lack insight may require more focused direction. ${ }^{16}$ However, Competence Committees will be relying on clear written feedback to assess their resident's readiness to move to the next stage further highlighting the importance of written feedback. ${ }^{17}$

This study has implications for internal medicine programs as they transition to CBD. Guidelines on providing feedback in a clinical education setting strongly recommend providing actionable feedback, enabling the learner to improve and address gaps in their knowledge. ${ }^{18}$ Central to feedback is the concept that it must be a collaborative process between both parties. ${ }^{19}$ Templates have been developed to facilitate the feedback process. For example, the R2C2 model (Relationship, Reactions, Content, Coach) has been shown to be an effective feedback mechanism for aggregate data. ${ }^{20} \mathrm{An}$ "in the moment" (itM) version, developed to be used with EPAs or to provide feedback at the end of a clinical day or following a procedure, guides assessors through the same four stages. ${ }^{21}$ The itM version recognizes that with less time, the identification of content and coaching will need to be more focused on ensuring residents receive actionable feedback and the assessor can coach for that. ${ }^{22}$ Going forward, there will be a need for local residency programs to offer faculty development on approaches to providing feedback including coaching techniques and examining the impact of this in a scholarly way. ${ }^{10,22-23}$

There are limitations to this project. The study was limited to one site, the University of Calgary, and to one specialty, core IM. Initially, we launched the CBD process with internal medicine residents in their PGY-1 academic year. Therefore, the early experiences with CBD described here only account for approximately one-third of the core IM cohort in Calgary. With the exception of the time taken to complete the form, we did not assess assessors' perceptions. In addition, a number of EPA

Table 4. Examples of nonactionable and actionable written feedback provided for EPA 4 (discharge planning in acute care).

Examples of nonactionable written feedback from
EPA 4
"the trainee presented the plan clearly to the patient, answering
appropriately to the questions posed by the patient and
demonstrating very good communication skills"
"great communication and down to earth"
"thorough patient communication"
"done in an efficient and timely fashion"
"excellent bedside skills and appropriate conversation with patient"
"very good communicator"

Examples of nonactionable written feedback from
Examples of actionable written feedback from EPA 4

"Overall doing well. Suggestions made to signpost and get patient to reiterate plan to ensure they understand what happened in hospital and what the path forward is"

"I gave feedback and suggestions on improvement (clarity of the follow-up appointment with the specialist)"

"plan should incorporate consideration of weaning beta blocker in patient no longer in atrial fibrillation" 
submissions were excluded from analysis of value and disruption due to indeterminate answers or a lack of comments. This is likely because our questions were general (see Table 2, Question 12), and many residents did not specifically address both value and disruption. While assessors were asked for the "time required to provide feedback and to complete the form," it is possible they included the time for observation of the trainee. Therefore, the wide range could be explained by an increased time for directly observed EPAs compared to indirectly observed EPAs.

\section{Conclusion}

This study is an important step in understanding EPA feedback and actionability within CBD. Frequent, observed, low-stake's encounters are important to help coach residents, but residents may still not be receiving written actionable feedback despite this framework. This study highlights the potential ongoing need for faculty development to ensure that feedback is actionable so as to help trainees improve future performance.

\section{References}

1. Carraccio C, Englander R, Van Melle E, et al. International CompetencyBased Medical Education Collaborators. Advancing Competency-Based Medical Education: A Charter for Clinician-Educators. Acad Med. 2016; 91(5):645-9. doi: http://dx.doi.org/10.1097/ACM.0000000000001048.

2. Lockyer J, Carraccio C, Chan MK, et al. ICBME Collaborators. Core principles of assessment in competency-based medical education. Med Teach. 2017; 39(6): 609-616. doi:http://dx.doi.org/10.1080/01421 59X.2017.1315082.

3. Harris P, Bhanji F, Topps M, et al. ICBME Collaborators. Evolving concepts of assessment in a competency-based world. Med Teach. 2017 Jun; 39(6): 603-608. doi: http://dx.doi.org/10.1080/0142159X.2017.1315071.

4. Royal College of Physicians and Surgeons of Canada., Competence by Design [Internet]. Ottawa, Canada. [cited 2020 Mar 21]. Available from: http://www.royalcollege.ca/rcsite/cbd/competence-by-design-cbd-e. Accessed: March 21, 2020

5. Royal College of Physicians and Surgeons of Canada., Understanding Workplace-Based Assessment and CBD [Internet]. Ottawa, Canada. [cited 2020 Mar 21]. Available from: http://www.royalcollege.ca/rcsite/cbd/ assessment/cbd-work-based-assessment-wbas-e. Accessed: March 21, 2020

6. Kwan BYM, Mbanwi A, Cofie N, et al. Creating a Competency-Based Medical Education Curriculum for Canadian Diagnostic Radiology Residency (Queen's Queen's Fundamental Innovations in Residency Education)-Part 1: Transition to Discipline and Foundation of Discipline Stages. Can Assoc Radiol J. 2020 Mar 4: 846537119894723 . doi: http://dx .doi.org/10.1177/0846537119894723.

7. Stahl CC, Collins E, Jung SA, et al. Implementation of Entrustable Professional Activities into a General Surgery Residency. J Surg Educ. 2020;77(4):739-48 Feb 8. pii: S1931-7204(20)30012-X. doi: http://dx.doi. org/10.1016/j.jsurg.2020.01.012. [Epub ahead of print] PubMed PMID: 32044326.

8. Martin L, Sibbald M, Brandt Vegas D, et al. The impact of entrustment assessments on feedback and learning: Trainee perspectives. Med Educ. 2019 Dec 15;54(4):328-36. doi: http://dx.doi.org/10.1111/medu.14047. [Epub ahead of print] PubMed PMID: 31840289.

9. Hatala R, Ginsburg S, Hauer KE, et al. Entrustment Ratings in Internal Medicine Training: Capturing Meaningful Supervision Decisions or Just Another Rating? J Gen Intern Med. 2019 May; 34(5): 740-743. doi: http:// dx.doi.org/10.1007/s11606-019-04878-y. PubMed PMID: 30993616; PubMed Central PMCID: PMC6502893.

10. Crawford L, Cofie N, McEwen L, et al. Perceptions and barriers to competency-based education in Canadian postgraduate medical education. J Eval Clin Pract. 2020;26(4):1124-31 Feb 27. doi: http://dx.doi.org/10.1111/ jep.13371. [Epub ahead of print] PubMed PMID: 32106354.

11. Branfield Day L, Miles A, Ginsburg S, et al. Resident Perceptions of Assessment and Feedback in Competency-Based Medical Education: A Focus Group Study of One Internal Medicine Residency Program. Acad Med. 2020;95(11):1712-17 Mar. doi: http://dx.doi.org/10.1097/ ACM.0000000000003315. [Epub ahead of print] PubMed PMID: 32195692.

12. Hawkins RE, Welcher CM, Holmboe ES, et al. Implementation of competency-based medical education: Are we addressing the concerns and challenges? Med Educ. 2015; 49(11): 1086-102. doi: http://dx.doi .org/10.1111/medu.12831.

13. Tomiak A, Braund H, Egan R, et al. Exploring How the New Entrustable Professional Activity Assessment Tools Affect the Quality of Feedback Given to Medical Oncology Residents. J Cancer Educ. 2020 Feb;35(1):165-177. doi: http://dx.doi.org/10.1007/s13187-018-1456-z.

14. Bing-You R, Hayes V, Varaklis K, et al. Feedback for learners in medical education: What is known? A scoping review. Academic Medicine. 2017 Sept; 92(9): 1346-1354. doi: http://dx.doi.org/10.1097/ACM.0000000000001578. PubMed PMID: 28177958.

15. Nash RA, Winstone NE, Gregory SEA, et al. (2018). A memory advantage for past-oriented over future-oriented performance feedback. Journal of Experimental Psychology: Learning, Memory, and Cognition. 2018 Mar; 44(12): 1864-1879. http://dx.doi.org/10.1037/xlm0000549.

16. Roze des Ordons A, Cheng A, Gaudet J, et al. Adapting Feedback to Individual Residents: An Examination of Preceptor Challenges and Approaches. J Grad Med Educ. 2018 Apr; 10(2): 168-175. doi: http://dx.doi. org/10.4300/JGME-D-17-00590.1. PubMed PMID: 29686756; PubMed Central PMCID: PMC5901796.

17. Ginsburg S, van der Vleuten CP, Eva KW, et al., Cracking the code: Residents" interpretations of written assessment comments. Med Educ. 2017 Apr;51(4):401-410. doi: http://dx.doi.org/10.1111/medu.13158. Epub 2017 Jan 16.

18. Lefroy J, Watling C, Teunissen PW, et al. Guidelines: The do's, don'ts and don't knows of feedback for clinical education., Perspect Medical Education. 2015; 4:284-299. doi http://dx.doi.org/10.1007/s40037-015-0231-7.

19. Ajawi R, and Regehr G., When I say... feedback., Medical Education. 2019;53(7):652-654, 21 October 2018,. http://dx.doi.org/10.1111/ medu. 13746.

20. Sargeant J, Lockyer JM, Mann K, et al. The R2C2 Model in Residency Education: How Does It Foster Coaching and Promote Feedback Use? Acad Med. 2018 Jul; 93(7):1055-1063. doi: http://dx.doi.org/10.1097/ ACM.0000000000002131.

21. Lockyer J, Armson H, Könings KD, et al. In-the-Moment Feedback and Coaching: Improving R2C2 for a New Context. J Grad Med Educ. 2020 Feb;12(1):27-35. doi:http://dx.doi.org/10.4300/JGME-D-1900508.1. PubMed PMID: 32089791; PubMed Central PMCID: PMC7012514.

22. Armson H, Lockyer JM, Zetkulic M, et al. Identifying coaching skills to improve feedback use in postgraduate medical education., Medical Education. 2019 May; 53(5):477-493. doi: http://dx.doi.org/10.1111/ medu.13818.

23. Crawford L, Cofie N, McEwen L, et al. Perceptions and barriers to competency-based education in Canadian postgraduate medical education. J Eval Clin Pract. 2020 Feb 27. doi: 10.1111/jep.13371. [Epub ahead of print] PubMed PMID: 32106354.

24. Nousiainen MT, Caverzagie KJ, Ferguson PC, et al.; ICBME Collaborators. Implementing competency-based medical education: What changes in curricular structure and processes are needed? Med Teach. 2017 Jun; 39(6): 594-598. doi: http://dx.doi.org/10.1080/0142159X.2017.1315077. PubMed PMID: 28598748. 